Psychology for Professional Groups PSYCHOLOGY FOR TEACHERS 
Psychology for Professional Groups

Series editors: Antony J. Chapman and Anthony Gale

Psychology for Professional Groups is a well-established textbook series providing the full range of current scientific expertise on the psychology available to professionals, whether practising or in training for qualifying examinations.

Other titles:

Psychology for Managers (2nd edn) edited by Cary L. Cooper and Peter Makin

Psychology for Social Workers (2nd edn) edited by Martin Herbert

Psychology for Nurses and Health Visitors edited by John Hall

Psychology for Occupational Therapists edited by Fay Fransella

Psychology for Speech Therapists edited by Harry W. Purser

Psychology for Physiotherapists edited by E.N. Dunkin

Psychology and People: A tutorial text edited by Antony

J. Chapman and Anthony Gale

Psychology and Medicine edited by David Griffiths 
Psychology for Professional Groups

\section{PSYCHOLOGY FOR TEACHERS}

$\overline{\text { Second Edition }}$

\section{David Fontana}

Reader in Educational Psychology

University College Cardiff

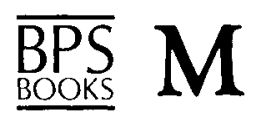

Published by

The British Psychological Society in association with Macmillan Education 
Published by The British Psychological Society, St Andrews House, 48 Princess Road East, Leicester, LE1 7DR, UK, in association with Macmillan Publishers Ltd, Basingstoke.

Copyright (C) The British Psychological Society 1981

(C) David Fontana 1988

First published 1981

Reprinted 1982, 1983, 1985, 1986

Second edition 1988

All rights reserved. No part of this publication may be reproduced or transmitted, in any form or by any means, without permission.

This book is sold subject to the condition that it shall not, by way of trade or otherwise, be lent, resold, hired out, or otherwise circulated without the publisher's prior consent in any form of binding or cover other than that in which it is published and without a similar condition including this condition imposed on the subsequent purchaser.

British Library Cataloguing in Publication Data

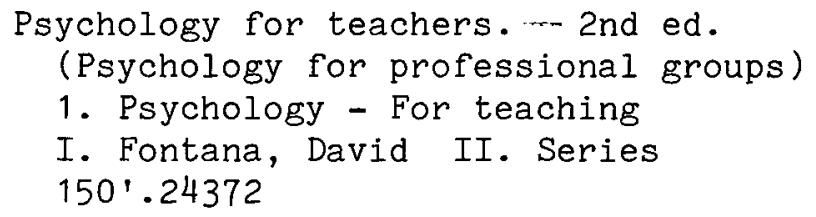

ISBN 978-0-333-46125-9

ISBN 978-1-349-19213-7 (eBook)

DOI 10.1007/978-1-349-19213-7

Whilst every effort has been made to ensure the accuracy of the contents of this publication, the publishers and author expressly disclaim responsibility in law for negligence or any other cause of action whatsoever. 


\section{Contents}

Introduction to First Edition $\mathrm{xi}$

Introduction to Second Edition $\mathrm{xv}$

\section{PART I THE EARLY YEARS}

\section{Early Social Development 3}

The child in the home 3

The influence of attachment upon later development 4 The nature of early social learning 7

Sex roles 8

Ethnic groups 10

Social class 11

The family 13

The changing nature of the family 14

Neglected children 15

Family conflict 16

The home-school conflict 19

Specific classroom issues 20

Language and social development 21

Gender differences 23

Ethnic factors 24

The home and the school 25

SOME QUESTIONS 27

\section{Play 29}

The purpose of play 29

The nature of play 30

Categories of play 31

Play and learning 32

Play and the curriculum 34

Structuring young children's play 35

Older children's play 36

Sport 37

SOME QUESTIONS 38

\section{PART II COGNITIVE FACTORS AND LEARNING}

\section{Concept Formation and Development 43}

Thinking and education 43

The work of Piaget 43

Stage 1. Sensori-motor (birth to two years) 44

Stage 2. Pre-operational thought (2-7 years) 45

Stage 3. Concrete operations (7-11 years) 47

Stage 4. Formal operations (12 years and upwards) 48 
Criticisms of Piaget 50

Other approaches to cognitive development 52

Cognitive development and the classroom 54

The task of the teacher 54

SOME QUESTIONS 57

\section{Language 61}

The beginnings of language 61

Encouraging early language 65

Language and the school 66

The role of the teacher 67

The rules of language 68

The importance of language teaching 68

Teacher questions 69

Teacher language 70

Dialects and accents 72

Enhancing language skills 72

The teacher as listener 73

Language games 74

Reading and writing 75

Language and intelligence 76

SOME QUESTIONS 77

\section{Intelligence 79}

What is intelligence? 79

The measurement of intelligence 79

Intelligence testing - origins and later developments 81

Models of intelligence 85

The measurement of general intelligence (' $\mathrm{g}$ ') 86

The usefulness of ' $\mathrm{g}$ ' 87

Can IQ be enhanced? 88

Coaching for IQ tests 89

IQ tests and the teacher 90

Improving intelligence 91

Intelligence and thinking 93

Is intelligence inherited? 94

Twin studies 96

Other studies 98

The approaches of Hebb and Cattell 100

Intelligence and ethnic groups 101

Intelligence and socio-economic factors 103

Urban and rural differences in intelligence 104

Gender differences in intelligence 104

SOME QUESTIONS 107

\section{Creativity 111}

What is creativity? 111

Lateral/divergent thinking 111

Creativity and intelligence 112

Divergent thinking tests 114

The creative act 115 
Creativity and the school 118

Encouraging divergent thinking 118

Classroom organization and creativity 119

Creative teaching techniques 120

SOME QUESTIONS 123

\section{Learning 125}

What constitutes learning? 125

Theories of learning 127

Operant conditioning 127

Instrumental conceptualism 128

The nature of the learner 131

Affective factors 131

Motivation 133

Age, gender and social factors 134

Memory 136

Study habits 138

The nature of the material to be learned 140

The cognitive domain 141

The affective domain 143

The psychomotor domain 143

Assessment 144

The nature of the learning process 146

Managing the learning process 150

Precision teaching 150

The 'slow learner' 151

Children with low IQ scores 152

Teaching children with low IQ scores 154

Children retarded in achievement $\mathbf{1 5 5}$

Helping children retarded in achievement 158

SOME QUESTIONS 161

\section{PART III AFFECTIVE FACTORS}

\section{Personality 167}

The origins of personality 167

The role of parents 169

The enduring nature of temperament 169

Approaches to personality 170

Ruler or thermometer? 171

Personality traits 171

The work of H.J. Eysenck 172

The work of R.B. Cattell 173

Pros and cons of the trait-based approach 174

Personality traits and learning 175

The extraversion-introversion dimension 175

The neuroticism-stability dimension 176

The trait-based approach and individual differences 178

Modifying personality traits 179

Personality and academic success 180

Cognitive style 181 
Theories of cognitive style 182

Cognitive style and learning 186

Personality states 186

Arguments against permanence in personality 187

Telic-paratelic behaviour 188

The state-based approach and counselling 189

The psychodynamic approach 190

Sigmund Freud - the id - the ego - the super ego - ego

defence mechanisms - three kinds of anxiety 190

Personality and motivation 195

Motivation and reinforcement 196

Maslow's theory of motivation 196

Locus of control 198

The teacher's reaction to success and failure in children 199

Mood 200

Teachers have moods too 201

Interest 202

Attitudes 204

Attitudes and ego defence 205

Attitudes and behaviour 206

Cognitive dissonance 206

Attitude change 207

SOME QUESTIONS 210

\section{Values and Moral Development 213}

What are morals and values? 213

The origins of value systems 213

Kohlberg's six stages of moral development 215

Measuring moral development 216

Criticisms of Kohlberg 217

The role of the teacher 218

Some specific moral problems 219

Teaching moral behaviour 221

SOME QUESTIONS 222

\section{The Self 225}

Defining the self 225

What determines the self? 227

The importance of learning in self-concepts 227

Can we know our real self? 228

Carl Rogers's theory of self 229

Conflict between the organism and other people 230

Measuring the self 231

George Kelly and the self 232

Constructs can be changed 236

Self-esteem 236

The development of self-esteem 236

Causal factors in self-esteem 238

Value to the teacher 238

Other influences on self-esteem 239

Encouraging self-esteem 240

Self-esteem is not the same as conceit 241 
Assessing self-esteem 242

Self-esteem and overassertion 243

Self-maturity 243

Erikson's eight stages and personal maturity 244

Children's ages and Erikson's stages 245

Self-maturity and the school 246

Defining the mature personality 247

Self-identity 248

Learning to be adult 249

Understanding the adolescent 250

Role confusion 251

Knowing and being 252

SOME QUESTIONS 253

\section{PART IV SOCIAL INTERACTION, TEACHER-CHILD RELATIONS AND TEACHER PERSONALITY}

\section{Social Behaviour and Social Skills 259}

Dyadic interactions 259

Social interaction between teacher and child 262

Social status 262

Social status and the school 265

Unnecessary assertion of teacher status 266

Social conformity 266

Non-conformity 267

The peer group 269

The school and conformity 270

The lesson as a social encounter 270

Teacher awareness of social interaction 271

The five-step episode sequence 273

The nature of communications 274

Interaction analysis 275

Social roles 278

Role conflict 279

Social learning and role models 280

Copying role models 282

Friendship patterns in the classroom 283

Classroom subgroups 284

Unsuitable friendships and the friendless child 285

The popular child 286

Sociometry 287

Social skills 288

Assertiveness 289

Assessing and responding to social situations 290

The right atmosphere for social skills training 292

Lessons learnt from role playing 293

The importance of social warmth 294

The place of self-disclosure 294

SOME QUESTIONS 296 
12 Educational Guidance and Counselling 299

Counselling in school 299

The problem of confidentiality 300

The importance of sympathy 302

The counselling process 303

Categorizing the child's problem 303

The role of the counsellor 304

Problems facing the counsellor 306

Social forces and conflicts 307

Vocational guidance 309

Developmental stages in career choice 310

The role of the counsellor in vocational guidance

Vocational guidance tests 313

SOME QUESTIONS 314

\section{Class Control and Management 317}

Problem behaviour 317

Defining problem behaviour 317

Behaviour modification techniques 319

The origins of undesirable target behaviours 320

Identifying both sides of the problem 322

Objections to behaviour modification techniques

The token economy 326

General points on behaviour modification 328

Other aspects of class control and management 329

The application of punishment 335

Effective sanctions 335

The law of natural consequences 337

Group behaviour problems 338

Physical confrontation 339

School refusal 340

SOME QUESTIONS 342

\section{Teacher Personality and Characteristics 345}

Teacher effectiveness 345

Assessing teacher characteristics 346

Emotional security in the teacher 348

Teacher attitudes 349

Teacher styles 350

The value of teacher talk 351

Introducing variety into teaching methods 352

Flexibility 353

Teacher stress 353

How to handle stress 355

SOME QUESTIONS 358 


\section{Introduction to First Edition}

The purpose of this book is to acquaint the reader with those areas of psychology of most practical value to the teacher. It deals, therefore, not only with matters relating directly to the classroom, but with matters pertaining to the child's background outside school and to his or her own self-perceptions and self-concepts. The teacher's task can only be clarified if he or she has a knowledge of children as complete persons rather than simply as individuals who spend the hours from nine o'clock until four sitting in classrooms. The child's personality, ability to learn, motivation, social behaviour, and attitudes towards school are all formed as a consequence of a complex set of interrelated factors which begin at birth (and even before) and extend throughout each moment of waking life. By the time you have finished this book you should have a clear idea of what these factors are, and of how they influence child behaviour. You should also have a clear idea of the part you as teacher can play in the determination of this behaviour, and of how you can best help children to benefit from the learning opportunities that school has to offer.

The application of psychology to education has a long and honoured history, and stretches back to the first occasion when adults tried to influence the behaviour of the young. But it is only in comparatively recent years that the association between the two subjects has been given a firmly scientific basis. By this I mean that it is only during the last 60 years or so that psychology has developed the precision and methodology that allow it to make accurate generalizations about child behaviour, and to provide the teacher with the kind of information necessary if he or she is to make objective professional decisions and judgements. Without such information, the teacher can only fall back upon the sort of anecdotal evidence that we often hear when people are discussing children. We hear, for example, that children are supposed to be basically honest (or dishonest), that they like (or do not like) firm discipline, that they have (or have not) a sense of fair play, that they learn best in informal (or in formal) teaching environments, that they are influenced (or not influenced) by 
what they see on television and so on. One school of thought has it that children's behaviour is the result of conditioning, another that they have the freedom to decide for themselves. We are told on the one hand that abilities such as intelligence are largely inherited, and on the other that they are largely the result of environmental influences. Small wonder that faced with such conflicting statements inexperienced teachers often feel confused, and decide in the end that they must make up their own minds on these and other important matters.

It would be wrong to suggest that modern psychology has final answers to all the questions that face us in education. Children (and teachers) are individuals, and often must be studied as individuals before detailed guidance on particular problems can be given. And, in any case, there are still large gaps in our knowledge that remain to be filled. Human behaviour is very complex and its measurement and assessment fraught with many difficulties. It is in fact this very complexity that gives the study of psychology much of its fascination. But psychology helps teachers recognize the factors that influence child behaviour and learning, and assists them in developing strategies to cope with the tasks that must be faced in the classroom. Furthermore, it helps the teacher to examine his or her own general professional behaviour, and to identify areas where this behaviour may itself have contributed towards particular problems that may have arisen. As is stressed repeatedly throughout the book, psychology shows us that no child's behaviour can be fully understood unless we study also the behaviour of others - teachers, parents, school friends - towards that child. Each individual stands at the centre of a complex matrix of interrelated influences, each of which must be taken into account if we are to comprehend the way in which the individual lives his or her life. In the case of the child this matrix is of particular importance. Still at an early formative stage in development, the child is very much dependent upon other people's behaviour. When the teacher, for example, speaks critically of the child's performance in a particular subject, the child may get the impression that this indicates he or she lacks ability in it, and that future performance may deteriorate even further. If we are to help that child improve his or her standards we must look therefore not only at the gaps in their knowledge but at the way in which the teacher, albeit unwittingly, has been undermining the child's confidence in his or her own potential.

Psychology also helps us answer some of the questions on the origins of individual differences. Are we born different, or do we simply become different as the result of experience? Put another way, are individual differences genetically or environmentally determined? By individual differences we mean not only intelligence but also such things as personality, creativity and motor skills. As we shall see, these answers are of critical 
importance for the teacher since they indicate some of the limits to the influence which education can have upon our lives. If individual differences are largely inherited then there is little that education can do beyond developing what is already there. If, on the other hand, these differences are mainly the result of environment, then education has an enormous potential to redress and alter the consequences of early disadvantage and to help all children achieve the same high standards.

The book deals with children from an early age through into adolescence and the end of compulsory schooling, but this does not mean that you should pick out only those sections that apply to the ages you plan to teach or are actually teaching. For a full understanding of older children the secondary school teacher needs to know something of the formative influences that have been at work during the early part of their lives, while the primary school teacher needs to know something of the problems that may lie ahead of children in their care in order to play a full part in helping them develop the skills and strategies necessary to cope with such problems. The book is designed for both serving teachers and students in training, and the emphasis throughout is upon the practicalities of the teacher's task. Thus theoretical areas of psychology that may be of interest in themselves but that have little real application for what the teacher actually does with children are avoided. A high premium is also placed upon clarity, so that the non-specialist should be able to read the book without experiencing undue difficulties in understanding any of the points raised. Finally, the book can be read as a whole or dipped into, depending upon the needs of the reader. The important thing is that it should be of some use.

\section{The plan of the book}

The plan of the book is simple. In Part I we look at early influences upon the child such as parent-child relationships, family size, and social class. Part II then examines cognitive factors (i.e. mental factors to do with thinking, intelligence and learning) while Part III looks at affective factors (i.e. emotional factors to do with personality, attitudes and values). Part IV looks at social factors: that is, at the factors involved in the child's relationships with the teacher and with the classroom group, and at the teacher him or herself, at what is known about the qualities that make the successful teacher and at the ways in which we study interaction between the teacher and the class.

Each chapter outlines current knowledge in the areas concerned and discusses practical implications for the teacher. At the end of each chapter there are suggestions for further 
reading, together with a list of questions and discussion points. These questions are not designed so much to test your factual knowledge as to draw attention to some of the most important issues discussed in the chapter and to start you thinking creatively about them.

David Fontana

University College Cardiff, 1981 


\title{
Introduction to Second Edition
}

A number of extensive alterations to the material contained in the first edition have been made. Some of this material, in keeping with the policy for the Psychology for Professional Groups series of which this book is a part, was by authors other than myself. These contributions do not appear in the new edition, as I have rewritten the topics covered by them with teacher education exclusively in mind. The convention in the first edition of dividing the theoretical content of each chapter from the practical content has also been changed in the new edition with the result that each chapter now links theory and practice closely together throughout.

Opportunity has also been taken in the new edition to amalgamate the two chapters on personality, since this further helps the linkage of theory and practice. Across a wide area of subjects new sections have also been added, for example on early attachment, ethnic groups, neglected children, the home-school conflict, language and the school, teacher language, approaches to personality, personality states, measuring the self, social status, social roles, social skills and teacher stress. In addition, each part of the book has been thoroughly revised and updated, in the light both of current developments within the field of educational psychology and the feedback to the first edition obtained from students, practitioners and book reviewers. It is the hope of the publishers, the series editors and myself that these extensive alterations will further strengthen the book's usefulness both to student and to serving teachers.

\author{
David Fontana \\ University College Cardiff, 1988
}

